\title{
Experimental Research on Passive Control of Steel Frame Structure Using SMA Wires
}

\author{
Shi Yan, ${ }^{1,2}$ Jian Niu, ${ }^{1,2,3}$ Peng Mao,, ${ }^{1,4}$ Gangbing Song, ${ }^{2,5}$ and Wei Wang1 \\ ${ }^{1}$ School of Civil Engineering, Shenyang Jianzhu University, Shenyang 110168, China \\ ${ }^{2}$ Faculty of Infrastructure Engineering, Dalian University Technology, Dalian 116024, China \\ ${ }^{3}$ Commission for Discipline Inspection Supervision and Audit, Shenyang Agricultural University, Shenyang 110866, China \\ ${ }^{4}$ CAMCE WHU Design \& Research Co., Ltd., Wuhan 430073, China \\ ${ }^{5}$ Department of Mechanical Engineering, University of Houston, Houston, TX 77204, USA
}

Correspondence should be addressed to Jian Niu; 278244307@qq.com

Received 3 August 2013; Accepted 17 October 2013

Academic Editor: Gang Li

Copyright (c) 2013 Shi Yan et al. This is an open access article distributed under the Creative Commons Attribution License, which permits unrestricted use, distribution, and reproduction in any medium, provided the original work is properly cited.

\begin{abstract}
Mechanical properties of shape memory alloy (SMA) wires were experimentally researched in this paper, and an energy dissipater made of SMA wire cable was designed and applied in a steel frame structure model by using superelasticity characteristics of SMAs to passively reduce dynamic responses of the steel frame structure under seismic load. For the characteristics of large relative displacements between the stories of the steel frame structure on both diagonal ends and the consideration of initial prestrain effects of the SMA cables, three kinds of the whole control, the part control, and no control of the shaking table tests and numerical simulations were carried, respectively. Through the results of the shaking table test and numerical simulation analysis, the dynamic responses such as the maximum displacement, velocity, and acceleration at the top layer of the steel frame structure applied with SMA cables are significantly decreased compared with the no control case. However, considering the premise of both effectiveness and efficiency, the part control effect is superior to the whole control. In many cases, it can meet the control requirement of reducing the maximum displacement and acceleration, while the superelasticity of SMAs can be sufficiently played, realizing the passive control purposes of the steel frame structure based on the energy dispassion through the application of the SMA cables. The proposed method has broad application prospects in the passive control field of building structures.
\end{abstract}

\section{Introduction}

Compared with other metals, shape memory alloy (SMA) has superior automatic detection and adaptation, self-diagnosis and self repair, and other functions of intelligent materials, which have the typical shape memory effect (SME), superelasticity (SE), and high damping characteristics. The superelasticity property refers to the recovery feature of the SMAs as the external force generated when the load is greater than the elastic limit strain. This strain can be automatically recovered while unloading. The superelastic recoverable strain can reach up to $6 \sim 8 \%$ and the superelastic yield stress is controlled at $400 \sim 500 \mathrm{MPa}$. The superelastic properties make an SMA have larger hysteretic energy dissipation capacity. It can be used to make reduction, isolation, and energy dissipation dampers, which can be installed in specific areas of a structure to reduce or inhibit responses caused by dynamic loading [1]. Ni et al. [2] introduced a constitutive relationship of shape memory alloy to discuss the working principle of an SMA damper and produced an SMA damper for frame structure vibration control. They installed the energy dissipater in two layers of a frame structure model in the shaking table test. The results show that the energy dissipation effect is obvious and can significantly change the natural frequency of the frame structure. Li et al. [3] developed a new SMA damper by using the energy dissipation and fully recentring capacity ability of superelastic SMA wires. The test shows that the developed damper has the high efficient capacity of both the energy dissipation and the recentring function. Based on the damper design idea, $\mathrm{Li}$ et al. $[4,5]$ used the SMA superelasticity properties to come up with two new kinds of SMA dampers, the tensile type 
SMA damper and the scissor type SMA damper, respectively. Through energy dissipater design, the NiTi SMA wire used in the damper remains in the state of tension and avoids compression buckling in the process of vibration. A shaking table test for a five-floor steel frame where these dampers were installed was performed and the results show that these two new kinds of dampers have a very good damping effect. Han et al. [6] used the SMA superelasticity properties to design a new kind of damper to control the wind or earthquake induced responses. The experimental results show that the energy dissipation effect of this kind of energy dissipater can significantly change the natural frequencies of the frame structure. Using the SMA superelasticity properties, Xue et al. [7] presented an SMA composite friction damper by combining SMA wires with the friction damper; thus, the vibration response control of a single degree of freedom system installed in the SMA composite friction damper under seismic action is numerically simulated. The results show that the proposed SMA composite friction damper has excellent energy dissipation performance to reduce structural vibration responses. Yan et al. [8] summarized the advantages and disadvantages of the energy dissipation of SMAs and designed a new kind of SMA-viscous damper with the intensive energy dissipation and self-centring performance by using the superelasticity of the austenitic SMA.

The superelasticity performance of SMAs is used in this paper to propose an energy dissipation cable model and apply it in a steel frame structure, considering the prestrain effect, to carry out the shaking test and numerical simulation under three kinds of control methods, the whole control, the part control, and no control.

\section{Superelasticity Properties of SMA Wires}

The superelasticity property of SMA wires is observed when the temperature $T>A_{f}$; then the material will be in a fully austenitic state, stressing on the shape memory alloy to produce elastic deformation and it continues to impose stress to make it generate more inelastic deformation. This inelastic deformation can remain stable only under the effect of stress; it can then return to the former shape after unloading even without heating. The difference between ordinary metal material and the SMAs is that the recoverable strain of the SMA wire is large and presents an obvious nonlinear relationship between stress and strain. This behavior is called the superelasticity effect, as shown in Figure 1. The essence of an SMA that presents the superelasticity effect is the stress induced martensitic phase transformation. In addition, the relevant scholar research results show that the SMA, after heat treatment or mechanical treatment or cold deformation, will experience significant changes in its superelasticity effect. Therefore, according to the different usage conditions and requirements, SMA materials should be dealt with by means of certain "training" before the actual engineering application in order to make the superelasticity properties tend to be more stable.

2.1. One-Dimensional SMA Superelasticity Constitutive Relation Considering Strain Rate Effect. Since the late 1970s,

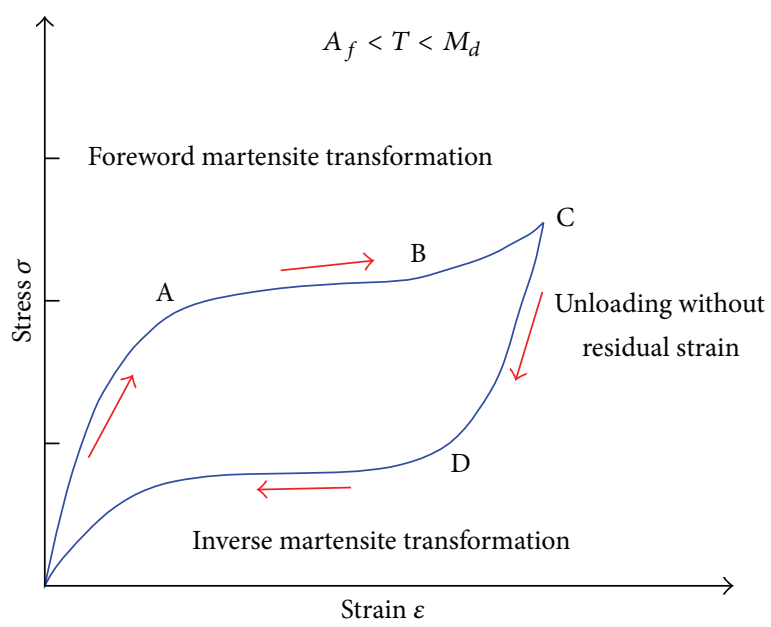

FIGURE 1: Stress-strain relationship and superelasticity effect of SMA.

some scholars set up a different constitutive models from a different angle. In 1986, Tanaka [9] developed a onedimensional incremental constitutive model for the SMA based on the basic law of thermodynamics and the constraint conditions. Then, Liang and Roger [10] simplified the model proposed by Tanaka and introduced the martensitic phase transformation in the development of a cosine function relation and established a one-dimensional full quantity type constitutive relation.

In order to describe the process of martensite preferred orientation, Brinson and Huang [11] presented assumptions that $\xi=\xi_{S}+\xi_{T}$ and put forward new thermodynamic equations including stress $\sigma$, strain $\varepsilon$, temperature $T$, and the percentage of martensite:

$$
\begin{aligned}
\sigma-\sigma_{0}= & D\left(\varepsilon-\varepsilon_{0}\right)+\Theta\left(T-T_{0}\right) \\
& +\Omega_{S}\left(\xi_{S}-\xi_{S 0}\right)+\Omega_{T}\left(\xi_{T}-\xi_{T 0}\right) .
\end{aligned}
$$

In formula (1) $D$ is of Young's modulus, $D=D_{A}+\xi\left(D_{M}-\right.$ $\left.D_{A}\right)$, and, among them, $D_{A}$ and $D_{M}$ are the austenite and martensite state of Young's modulus, respectively. $\Theta$ is the thermoelastic tensor, $\Omega$ is the phase transformation tensor, $\Omega=-\varepsilon_{L} D$, and, among them, $\varepsilon_{L}$ is the peak recoverable strain. $\Omega_{S}$ is the phase transformation tensor of stress; $\Omega_{T}$ is the phase transformation tensor of temperature. The subscript " 0 " indicates the initial state value of the material before force. $\xi_{S}$ and $\xi_{T}$ are the stress and temperature induced martensite percentage, respectively.

According to the passive control scheme of SMA cables, the temperature of SMA cables stays above the end of austenitic transformation temperature; that is $T>A_{f}$. At this time, the SMA is in the fully austenitic phase, expressing the exact superelasticity properties. And the temperature remains constant; that is $T=T_{0}$. Therefore, Brinson's constitutive equation can be rewritten as

$$
\sigma-\sigma_{0}=D\left(\varepsilon-\varepsilon_{0}\right)+\Omega_{S}\left(\xi_{S}-\xi_{S_{0}}\right)
$$


TABLE 1: Hysteretic energy dissipation performance test loading method.

\begin{tabular}{lccc}
\hline Test serial number & Test temperature & Loading method & Loading speed (mm/min) \\
\hline Test 1 & $T=20^{\circ} \mathrm{C}$ & Loop 30 times, \\
& & strain amplitude $6 \%$ & 30 \\
Test 2 & $T=20^{\circ} \mathrm{C}$ & $\begin{array}{c}\text { The maximum strain, respectively, } \\
\text { 3\%, } 4 \%, 5 \% \text {, and } 6 \% \text { of the cycle } \\
\text { time }\end{array}$ & 30 \\
\hline
\end{tabular}

The corresponding relations for the load induced $A \rightarrow M$ phase transition and unloading caused $M \rightarrow A$ phase change of the phase transition are shown as follows:

$$
\begin{aligned}
\xi_{S}= & \frac{1-\xi_{S 0}}{2} \cos \left\{\frac{\pi}{\sigma_{s}^{\mathrm{cr}}-\sigma_{f}^{\mathrm{cr}}}\left[\sigma-\sigma_{f}^{\mathrm{cr}}-C_{M} \times\left(T_{0}-M_{S}\right)\right]\right\} \\
& +\frac{1+\xi_{S 0}}{2} \\
& \xi_{S}=\frac{\xi_{S 0}}{2}\left\{\cos \left[a_{A}\left(T_{0}-A_{S}-\frac{\sigma}{C_{A}}\right)\right]+1\right\}
\end{aligned}
$$

In formula (4) $a_{A}=\pi /\left(A_{f}-A_{s}\right)$ is constant. Among them, $A_{S}$ and $A_{f}$ are, respectively, the beginning and end temperatures of the austenite phase transformation; $C_{M}$ and $C_{A}$ are, respectively, the material constant of martensitic phase transformation and austenite phase transformation; $\sigma_{s}^{\mathrm{cr}}$ and $\sigma_{f}^{\mathrm{cr}}$ are, respectively, the start and end critical stress of martensitic phase transformation; $M_{S}$ is the beginning temperature of martensitic; $\xi_{S 0}$ and $T_{0}$ are the initial value, respectively.

\subsection{Energy Dissipation Test for Superelastic SMA Wires. An} experiment is performed to set up the stress-strain relation of SMA wires to validate the energy dissipation during a dynamic loading. The NiTi shape memory alloy wire produced by the Chinese Academy of Sciences' Institute of Metal Research is used in the experiment. The SMA wire has a close and atomic ratio of Ti- $50.9 \% \mathrm{Ni}$, its diameter is $0.8 \mathrm{~mm}$, the end temperature of its martensite phase transformation is $M_{f}=-102^{\circ} \mathrm{C}$, the start temperature of the $M_{s}=-64^{\circ} \mathrm{C}$, the austenitic phase transformation start temperature is $A_{s}=$ $-22^{\circ} \mathrm{C}$, and the end temperature is $A_{f}=-3.8^{\circ} \mathrm{C}$. The SANS microcomputer control electron universal testing machine was used. The specimen has a length of $240 \mathrm{~mm}$, and the distance between fixtures is $200 \mathrm{~mm}$. For the test process, the loading scheme uses the equal displacement control with a displacement controlled termination condition and the termination condition for the unloading process is controlled by force. The test process is automatically controlled and the test data is also automatically collected by a computer, as shown in Figure 2. In Figure 2, number 1 is the test table, number 2 is the SMA wire, and number 3 is the data acquisition system. Before the test, SMA wires will be trained under cycles of loading and unloading with the same strain amplitude. Then, these trained SMA wires will be tested under different strain amplitudes, using the load test method shown in Table 1.
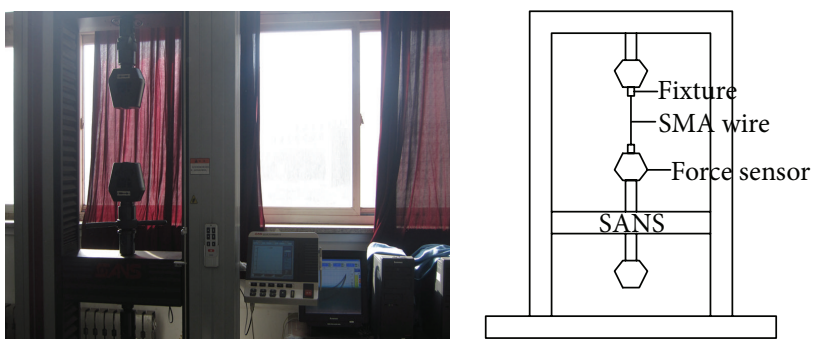

FIGURE 2: SMA superelasticity test setup.

The height of the hysteresis loop increases with increasing displacement amplitude, and the increment of the width increasing with the increase of the of the strain amplitude basically appears as a linear relationship. The "yield" stress is basically consistent during the stress induced martensite phase transformation (loading), but, during the inverse martensite phase transformation (unloading), a phenomenon of the "yield" stress going down occurs, as shown in Figure 3. After each cycle, the residual deformation of the SMA wire gradually decreases with the increase of the loading-unloading cycle number and the force-displacement curve gradually moves up. The residual deformation is close to zero starting from 10 cycles; after 20 cycles, the hysteresis curves tend to be stable, basically remaining in a curve, as shown in Figure 4. Therefore, before the engineering practical application, SMA wires should be put to a loading-unloading cycle training with certain displacement amplitude, and the SMA wires can guarantee to have stability with regard to the superelasticity properties.

2.3. Damper Design Based on SMA Superelasticity. The test model of vibration control for a three-story steel frame structure is designed. The height of the structure is $500 \mathrm{~mm}$, its thickness is $5 \mathrm{~mm}$, and all of the frame beams and frame columns adopt round steel pipes with an outer diameter of $8 \mathrm{~mm}$ and an inner diameter of $4 \mathrm{~mm}$. The dimensions of the structure with three stories are $600 \mathrm{~mm} \times 400 \mathrm{~mm} \times$ $1500 \mathrm{~mm}$, and each story has a $10 \mathrm{~kg}$ mass block placed on the floor. Beam-column joints are welded to each other, welding a $40 \mathrm{~mm} \times 40 \mathrm{~mm}$ square steel sheet in the node, and a round hole of $10 \mathrm{~mm}$ is drilled so as to conveniently install an SMA cable named the SMA superelasticity damper. According to the design of the model, the SMA superelasticity damper also adopts the hysteretic energy SMA wires produced by the Chinese Academy of Sciences' Institute of Metal Research, which were used in the dissipation performance test. The 


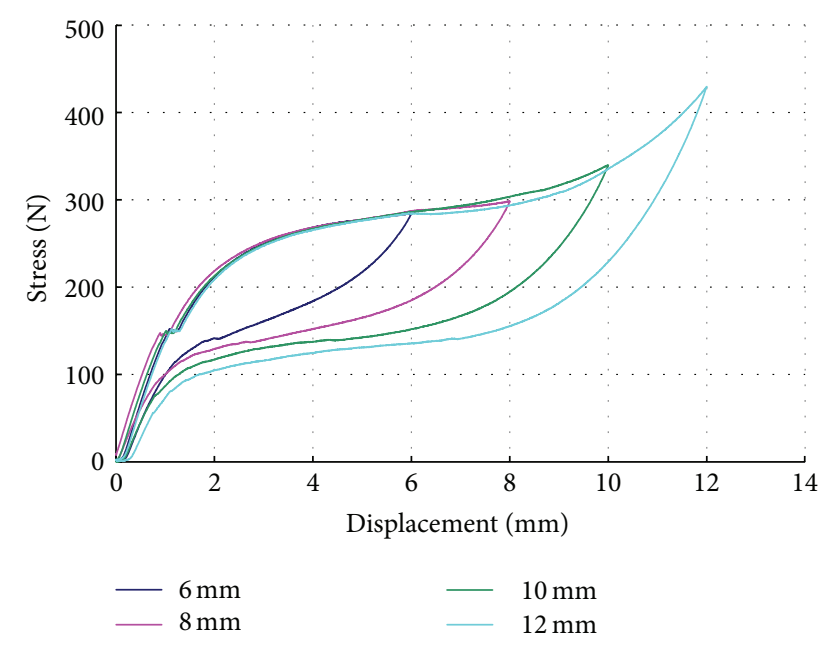

Figure 3: The relationship between stress and displacement for different maximum displacements.

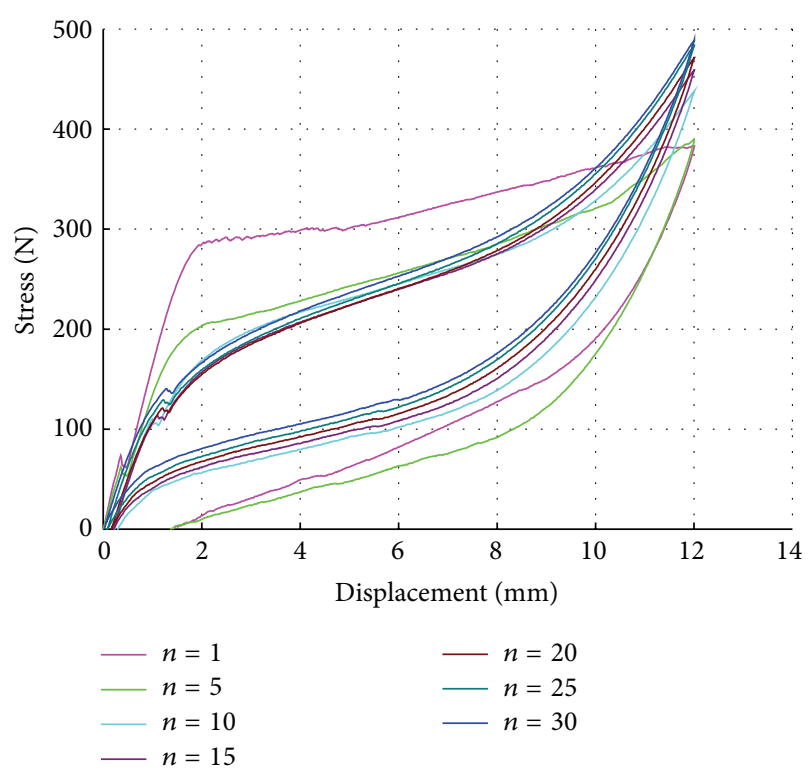

FIGURE 4: The relationship between stress and displacement for different loading cycles.

SMA wire diameter is $0.8 \mathrm{~mm}$, and the SMA superelasticity damper consists of 2 slices of steel sheet with a $40 \mathrm{~mm}$ width, $5 \mathrm{~mm}$ thickness, and a series of SMA wires $200 \mathrm{~mm}$ long, as shown in Figure 5. Because the steel sheet tensile stiffness is much larger than that of the SMA wire diameter of $0.8 \mathrm{~mm}$, it is assumed that all deformation will be generated by the SMA wires during the structural vibration.

\section{Passive Control Mechanism Using SMA Cables}

The passive energy dissipation mechanism using the proposed SMA dampers mainly includes two aspects: one is the energy dissipation mechanism due to the effect of internal

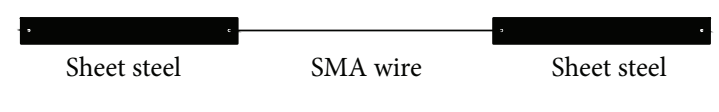

FIgURE 5: The superelasticity damper.

friction of the SMA itself; the other is the energy dissipation mechanism because of the superelasticity of SMA wires.

In order to make use of the SMA superelasticity effect to passively control structural vibration due to the random seismic load, the deformation of the structure under an earthquake load often has uncertainty, leading to a relaxation phenomenon of the SMA wire that easily occurs under stress, which is unable to give full play to its application. Therefore, the concept of the prestrain is introduced to the steel frame structure with the SMA wires in the passive control. While installing the SMA wires, a prestrain of the SMA wires is given in advance. This can guarantee that the SMA hysteresis loop will quickly come back to the center which can make full use of its hysteretic energy dissipation effect. Meanwhile, it can also guarantee that the SMA wires will always maintain tension during the vibration of the structure, increasing the control effect.

The principle of determining the initial working state of the wires can be described as [12].

Firstly, all of the SMA wires applied to the structure under earthquake excitation should be in a state of tension. In order to do this, the value of the initial strain $\varepsilon_{0}$ of each SMA wire should be determined. The maximum inelastic recovery strain of the SMA wire during hyperelastic phase transition is $8 \sim 10 \%$, and the SMA peak elastic strain is 3 4\%. In order to make the SMA wire rapidly enter into the state of superelasticity for absorption and dissipation of seismic energy in the process of an earthquake and at the same time make the SMA wires remain in the state of tension in the process of seismic response and not a compressive stress, the initial strain $\varepsilon_{0}=\varepsilon_{L} / 2$ of $4 \sim 5 \%$ is suggested.

Secondly, in the process of practical application of SMAs, the initial stiffness and relative displacement for the first modal vector in the middle story of the structure are directly proportional to the mass matrix product of the structure. This can realize the goal of making the SMA wires provide the maximum horizontal component force to the structure during an earthquake, which means that the seismic response of the structure can be obviously controlled due to the superelasticity of SMA wires.

Thirdly, the SMA wires in the same story of the structure should be ensured to have the same initial condition as soon as possible. Then, when the structural vibration is caused by a random strong seismic load, the structural displacement between the two adjacent stories will change. Therefore, the SMA wires on the diagonal between the layers of the two wires will also change. One wire tension stress will increase and the other will decrease. Accordingly, the sum of the vector of the loading and unloading wire tension forces in the horizontal direction at the same or neighboring stories are known as the effective control force for the SMA wires to apply to the steel frame structure, and the force can effectively reduce the seismic response of the structure such as 
acceleration, velocity, and displacement. In addition, because of the randomness of the direction of the seismic load, each SMA wire will be under different loading and unloading cycles according to the seismic response of the structure. From the superelasticity performance of SMA wires, it is shown that the stress and strain of wires in a continuous cycle keep constantly changing in the process of absorption and dissipation of seismic ability, so as to reduce the seismic response of the whole structure.

\subsection{The Equation of Motion of a Steel Frame Structure with} SMA Dampers. According to distribution characteristics of mass and stiffness of a frame structure, during the analysis of the structure for the whole control, the part control, and no control of the three kinds of structure forms, the basic assumption are put forward as follows [8].

(a) During an earthquake, displacements of all points at the structure bottom are the same at any time, regardless of the vertical component of ground motion as well as torsional vibration due to the misalignment of the centers of mass and stiffness of the structure itself.

(b) The floor slab and beam are assumed to be absolutely rigid, and the quality of each story is focused on the roof and the floor height, regardless of the column axial expansion. Therefore, only the horizontal vibration is considered for the floor.

(c) The SMA wire temperature change is ignored; namely, assume that the initial temperature of a wire $T_{0 j}$ on each cross-section of the wire and length direction is not change, keeping constant in the condition $T_{0 j}>$ $A_{f}$.

Based on the above assumptions, for the analysis of the dynamic response of a symmetrical and uniform structure, the structure is often simplified into a tandem particle structure system. However, to fully understand the mechanism of SMA damper's energy dissipation, an interstory shear model is used in this paper for the design of a steel frame structure with passive control, as shown in Figure 6.

When an earthquake occurs, the displacement and the acceleration of the ground are $X_{g}(t)$ and $\ddot{X}_{g}(t)$. Under the excitation of ground motion, the absolute displacement of the mass point of the structure is $Y_{i}(t)$ and the relative displacement is $X_{i}(t) Y_{i}(t)-X_{g}(t)$. The pulling force of every SMA wire is $F_{i j}(t)$. The sum of the horizontal component of the resultant force at each floor is the effective passive control force $U_{i}(t)$ of the SMA wire applied on the structure. According to the theory of structural dynamics [13] and its application in earthquake engineering, the equations of motion for three layers of a steel frame structure with SMA cable under earthquake excitation can be written as

$$
[M]\{\ddot{X}\}+[C]\{\dot{X}\}+[K]\{X\}=-[M]\{E\} \ddot{X}_{g}(t)+[B]\{U\} \text {. }
$$

In formula (5) $\{X\}$ is the structural displacement vector; $\{\ddot{X}\},\{\dot{X}\}$, and $\{X\}$ are the relative acceleration, velocity, and displacement matrix of the structure, respectively. $[M]$,
$[C]$ and $[K]$ are the mass matrix, damping matrix, and stiffness matrix of the structure, respectively. For a three-layer structure,

$$
\begin{gathered}
{[M]=\operatorname{diag}\left(m_{1}, m_{2}, m_{3}\right),} \\
{[K]=\left[\begin{array}{ccc}
k_{1}+k_{2} & -k_{2} \\
-k_{2} & k_{2}+k_{3} & -k_{3} \\
& -k_{3} & k_{3}
\end{array}\right] .}
\end{gathered}
$$

Using the Rayleigh damping assumption, $[C]=\alpha_{c}[M]+$ $\beta_{c}[K]$. In the formula $\alpha_{c}$ and $\beta_{c}$ are the coefficient determined by the structure natural frequency of $i$ and $j$ order modal $\omega_{i}$, $\omega_{j}$ and damping ratio $\xi_{i}, \xi_{j}$ which can be determined by the following equation:

$$
\begin{gathered}
\alpha_{c}=\frac{2 \omega_{i} \omega_{j}\left(\xi_{i} \omega_{j}+\xi_{j} \omega_{i}\right)}{\omega_{j}^{2}-\omega_{i}^{2}}, \\
\beta_{c}=\frac{2\left(\xi_{j} \omega_{j}+\xi_{i} \omega_{i}\right)}{\omega_{j}^{2}-\omega_{i}^{2}} .
\end{gathered}
$$

$\{E\}$ is the column vector of element 1 , and $-[M]\{E\}$ is the earthquake location matrix; $\{U\} \in[R]_{3 \times 1}$ is the matrix of the structure passive control and the position of the corresponding matrix is $[B] \in[R]_{3 \times 3}$ :

$$
\begin{aligned}
& {[B]=\left[\begin{array}{ccc}
1 & -1 & 0 \\
0 & 1 & -1 \\
0 & 0 & 1
\end{array}\right],} \\
& \{U\}=2\left\{\begin{array}{l}
u_{1} \\
u_{2} \\
u_{3}
\end{array}\right\}=2\left\{\begin{array}{l}
F_{11} \cos \theta_{11}-F_{12} \cos \theta_{12} \\
F_{21} \cos \theta_{21}-F_{22} \cos \theta_{22} \\
F_{31} \cos \theta_{31}-F_{32} \cos \theta_{32}
\end{array}\right\} .
\end{aligned}
$$

In the above formula $\theta$ is the angle of the SMA wire and horizontal floor; $\mathrm{F}$ is the tension of every SMA wire which depends on the strain state of each wire. That is, tensile loading condition $(A \rightarrow M)$, or tensile stress decreases of the unloading state $(M \rightarrow A)$. You can use the following formula into consideration [9].

$$
F_{j}\left(t, \xi_{s}\right)=\sigma_{j}\left(t, \xi_{s}\right) \cdot A_{j}\left(t, \xi_{s}\right) .
$$

In formula (10) $A_{j}\left(t, \xi_{s}\right)$ is the cross-sectional area of the " $j$ " wire at the time " $t$ "; $\sigma_{j}\left(t, \xi_{s}\right)$ is the tensile stress of the " $j$ " wire at the time " $t . "$

In time domain, structural motion equation can use a step-by-step integration method to determine the structural dynamic response.

\subsection{Numerical Analysis of Structural Vibration Control Based} on the SMA Wires. The model dimension and parameters for the numerical simulation are exactly the same with those of the subsequent shaking table test, and the steel frame model is shown in Figure 7. After the frequency spectrum analysis of the steel frame model under different control schemes, the natural frequency of the model is obtained under different control schemes as shown in Table 2. 


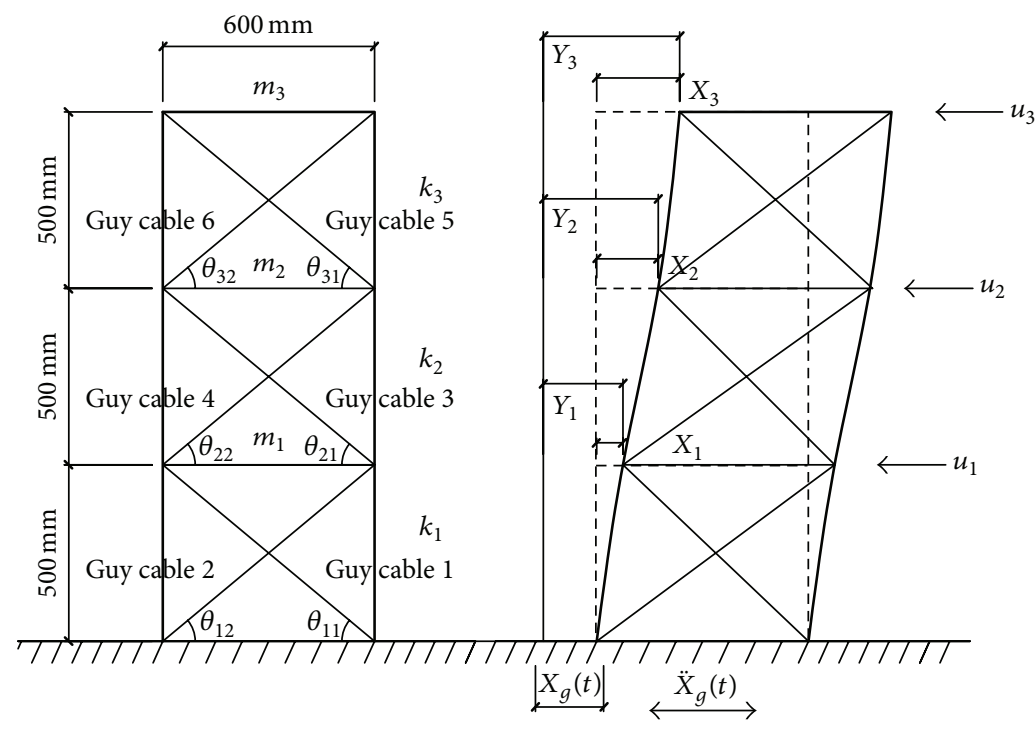

FIGURE 6: The schematic of three-layer steel frame structure installed SMA cables.

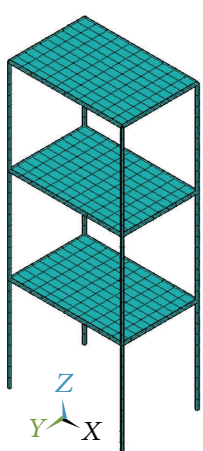

A0

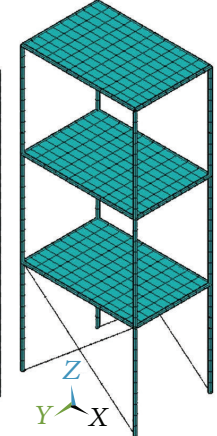

A1

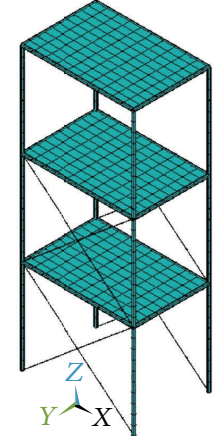

A2

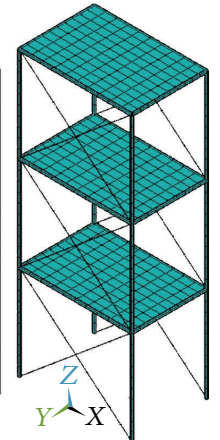

A3
FIGURE 7: Steel frame model for different control schemes.

TABLE 2: Inherent frequency and cycle of the 3-layer steel frame model under different control scheme.

\begin{tabular}{lcccc}
\hline Control scheme & I & II & III & IV \\
\hline Natural frequency/Hz & 1.6116 & 2.1009 & 3.7411 & 5.7067 \\
Cycle/s & 0.6205 & 0.4760 & 0.2673 & 0.1752 \\
\hline
\end{tabular}

Based on the analysis of the passive control mechanism and the equation of motion, two measured earthquake acceleration records are chosen for the numerical simulation and shaking table test. One chosen wave is Northridge, a far field wave, and the other is El Centro wave, a near field wave, and the parameters are shown in Table 3.

The above data shows that the natural frequency of the steel frame model installed SMA wire is improved with the model without SMA wire.

According to the current Code for Seismic Design of Buildings of China GB50011-2010, the amplitudes of two measured earthquake acceleration records are adjusted to

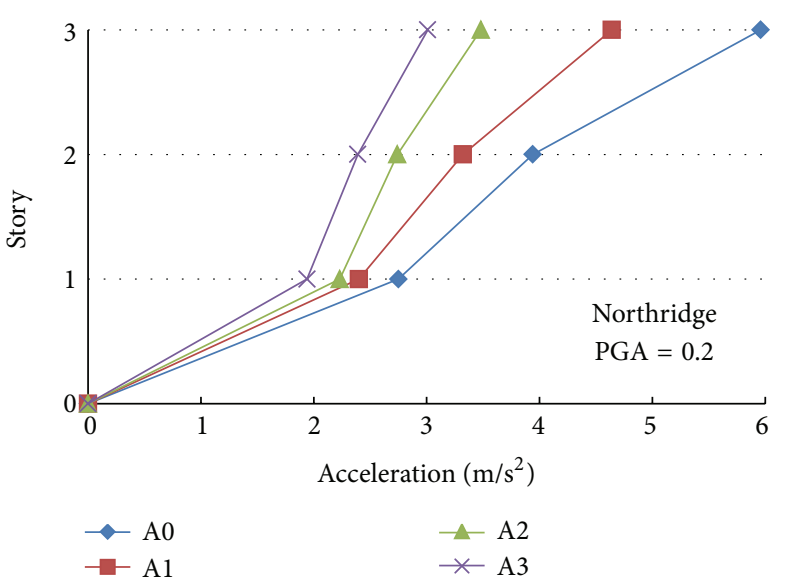

FIGURE 8: The peak acceleration for story under Northridge wave.

$0.20 \mathrm{~g}$. The loading is gradually increasing by a step of $0.05 \mathrm{~g}$ until it reaches $0.20 \mathrm{~g}$ for the shaking table test and numerical simulation.

The structural responses under the action of the two adjusted earthquake records along the $X$ direction are analyzed and the maximum acceleration and displacement of each story of the steel frame model under different control schemes are compared. For the maximum acceleration of the steel frame structure under the Northridge wave action with a maximum of $0.20 \mathrm{~g}$, the comparison of the peak acceleration is shown in Figure 8.

For the first floor, the maximum accelerations of schemes A0, A1, A2, and A3 are 2.75, 2.40, 2.23, and $1.94 \mathrm{~m} / \mathrm{s}^{2}$, respectively. For the second floor, the maximum accelerations of schemes A0, A1, A2, and A3 are 3.94, 3.32, 2.74, and $2.39 \mathrm{~m} / \mathrm{s}^{2}$, respectively. For the third floor, the maximum accelerations of schemes A0, A1, A2, and A3 are 5.96, 4.64, 3.48 , and $3.01 \mathrm{~m} / \mathrm{s}^{2}$, respectively. 
TABLE 3: Selection of seismic wave and the main parameters.

\begin{tabular}{lccccccc}
\hline Category & $\begin{array}{c}\text { Peak } \\
\text { acceleration/g }\end{array}$ & $\begin{array}{c}\text { Peak } \\
\text { speed/cm/s }\end{array}$ & $\begin{array}{c}\text { Peak } \\
\text { displacement/cm }\end{array}$ & $\begin{array}{c}\text { Frequency } \\
\text { range/Hz }\end{array}$ & The duration/s & $\begin{array}{c}\text { Record } \\
\text { points }\end{array}$ & $\begin{array}{c}\text { Time } \\
\text { interval/s }\end{array}$ \\
\hline Northridge & 0.604 & 78.2 & 16.05 & $0.12 \sim 23$ & 40 & 2000 & 0.02 \\
El-Centro & 0.519 & 46.9 & 35.35 & $0.1 \sim 40$ & 39.27 & 7857 & 0.005 \\
\hline
\end{tabular}

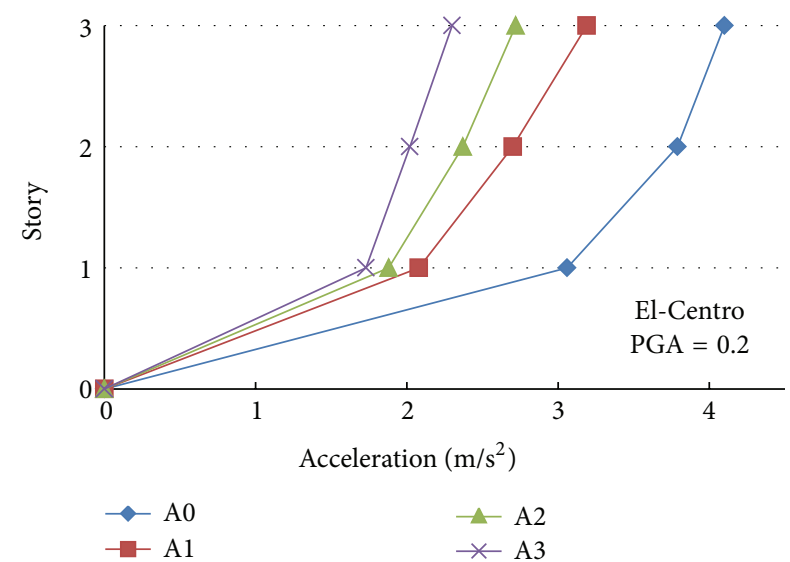

Figure 9: The peak acceleration for story under El-Centro wave.

For the maximum acceleration of the steel frame structure under the El-Centro wave action with a maximum of $0.20 \mathrm{~g}$, the comparison of the peak acceleration is shown in Figure 9.

For the first floor, the maximum accelerations of schemes $\mathrm{A} 0, \mathrm{~A} 1, \mathrm{~A} 2$, and $\mathrm{A} 3$ are $3.06,2.08,1.88$, and $1.73 \mathrm{~m} / \mathrm{s}^{2}$, respectively. For the second floor, the maximum accelerations of schemes A0, A1, A2, and A3 are 3.79, 2.70, 2.37, and $2.02 \mathrm{~m} / \mathrm{s}^{2}$, respectively. For the third floor, the maximum accelerations of schemes A0, A1, A2, and A3 are 4.10, 3.19, 2.72 , and $2.30 \mathrm{~m} / \mathrm{s}^{2}$, respectively.

For the maximum displacement of the steel frame structure under the Northridge wave action with maximum of $0.20 \mathrm{~g}$, the comparison of the peak displacement is shown in Figure 10. For the first floor, the maximum displacements of schemes A0, A1, A2, and A3 are 0.93, 0.65, 0.47, and $0.23 \mathrm{~cm}$, respectively; For the second floor, the maximum displacements of schemes A0, A1, A2, and A3 are 1.77, $0.84,0.65$, and $0.47 \mathrm{~cm}$, respectively. For the third floor, the maximum displacements of schemes $\mathrm{A} 0, \mathrm{~A} 1, \mathrm{~A} 2$ and $\mathrm{A} 3$ are $2.51,1.12,0.93$ and $0.74 \mathrm{~cm}$, respectively.

For the maximum displacement of the steel frame structure under the El-Centro wave action with maximum of $0.20 \mathrm{~g}$, the comparison of the peak displacement is shown in Figure 11. For the first floor, the maximum displacements of schemes A0, A1, A2, and A3 are 3.04, 0.57, 0.38, and $0.24 \mathrm{~cm}$, respectively. For the second floor, the maximum displacements of schemes A0, A1, A2, and A3 are 3.71, $0.86,0.67$, and $0.52 \mathrm{~cm}$, respectively. For the third floor, the maximum displacements of schemes $\mathrm{A} 0, \mathrm{~A} 1, \mathrm{~A} 2$, and $\mathrm{A} 3$ are $3.99,1.05,0.86$, and $0.67 \mathrm{~cm}$, respectively.

\section{Shaking Table Test and Result Analysis}

4.1. Test Model and Control Schemes. The test model is produced according to the goal of the experiment and the design

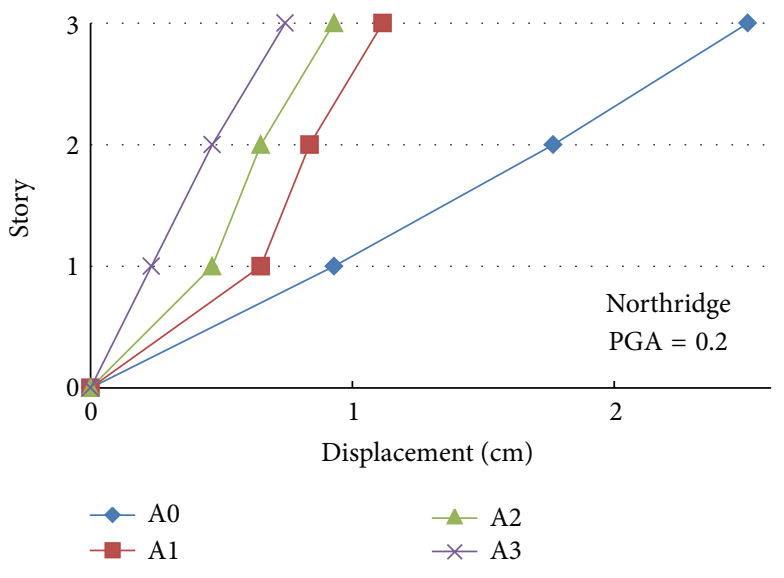

FIgURE 10: The peak displacement for story under Northridge wave.

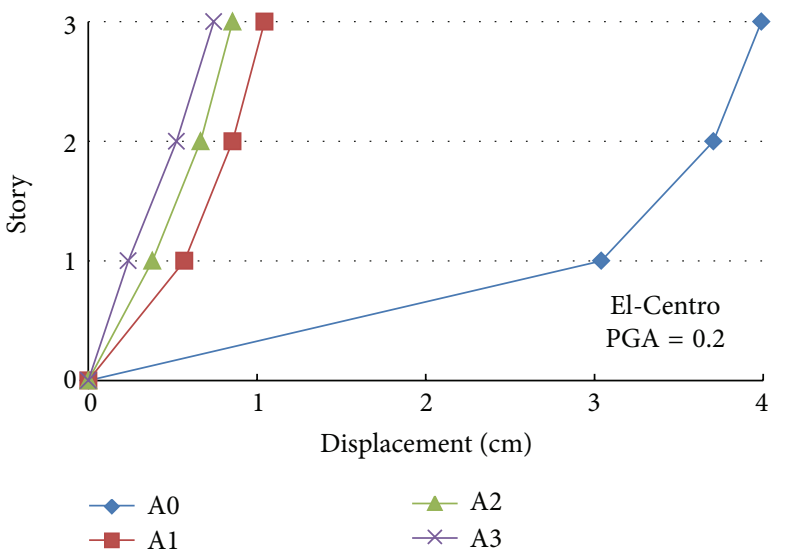

FIgURE 11: The peak displacement for story under El-Centro wave.

size. In the model of a three-story steel frame structure, each story has a mass block of $10 \mathrm{~kg}$ placed within. The total height of the model is $1.5 \mathrm{~m}$ and the detailed size is shown in Table 4 and Figure 12, respectively.

This paper studies the vibration control problem of the three-story steel frame structure for vibration along the $X$ direction. For the vibration of the frame structure, the relative displacement of two endpoints with a diagonal is the largest within a single story, and the SMA wire design and installation between two endpoints for real structure is more convenient. Therefore, the diagonal installation of the SMA wires is used for the shaking table test.

The loading device in the test is the Shake Table II-240 type vibration table, and the main parameters are length $x$ width $=1235 \times 1220 \mathrm{~mm}$ for the shaking table. When the maximum load is $100 \mathrm{~kg}$, the maximum acceleration can 
TABLE 4: Shaking table test model geometry size. Unit: mm.

\begin{tabular}{lcccccc}
\hline Layer number & $\begin{array}{c}\text { Model length } \\
(X)\end{array}$ & $\begin{array}{c}\text { Model width } \\
(Y)\end{array}$ & $\begin{array}{c}\text { Model height } \\
(Z)\end{array}$ & $\begin{array}{c}\text { Floor thickness } \\
\text { pipe inside diameter } \\
\text { size }\end{array}$ & $\begin{array}{c}\text { Beam and column } \\
\text { steel pipe outside } \\
\text { diameter size }\end{array}$ \\
\hline Frist floor & 600 & 400 & 500 & 5 & 4 & 8 \\
Second floor & 600 & 400 & 500 & 5 & 4 & 8 \\
Third floor & 600 & 400 & 500 & 5 & 4 & 8 \\
\hline
\end{tabular}

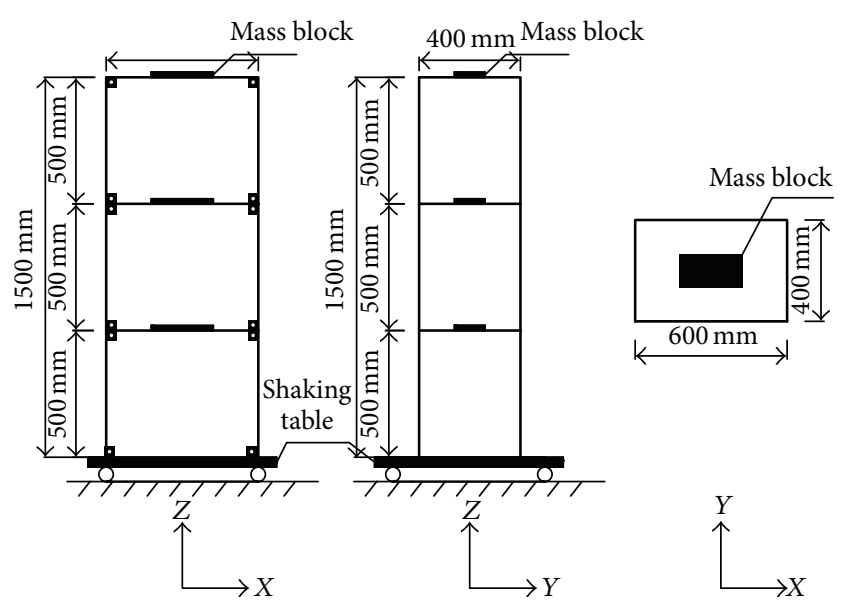

FIGURE 12: Shaking table test model dimensions.

reach $1.0 \mathrm{~g}$; the response frequency is $0-20 \mathrm{~Hz}$ (single axis); the maximum displacement is $119.7 \mathrm{~mm}$; length is $80 \mathrm{~cm}$, the distance between the two holes is $20 \mathrm{~cm}$, the short edge is $60 \mathrm{~cm}$, the distance between the two holes is $30 \mathrm{~cm}$, and the hole diameter is $10 \mathrm{~cm}$. During the test, the measured earthquake records are used and the load process is automatically controlled by computer, and the test data collection is also automatically collected. The acceleration sampling frequency for the data acquisition instrument is $200 \mathrm{~Hz}$, and the displacement sampling frequency is $1 \mathrm{kHz}$. The test setup is shown in Figure 13.

In order to compare the vibration response of the steel frame structure with or without SMA dampers as well as the influence of different number and location of SMA wires on the vibration response of the structure, it is required to look for a kind of economical and practical layout scheme of the SMA dampers for the passive control. Four kinds of control schemes are designed for comparison, as shown in Figures 14 and 15 . The scheme A0 denotes the case of no SMA wires; the scheme A1 is the case of only installing SMA dampers at the first floor; the scheme A2 presents the case of installing SMA dampers at both the first and the second floors; the scheme A3 demonstrates the case of installing SMA dampers at all of the three stories. For the variety of control schemes, the same seismic waves are input to verify the control effects.

4.2. Result Analysis. In order to determine the characteristics of the structure, the structural natural frequency experiment was carried out. The built-in harmonic vibration program in the shaking table control system is used to generate a

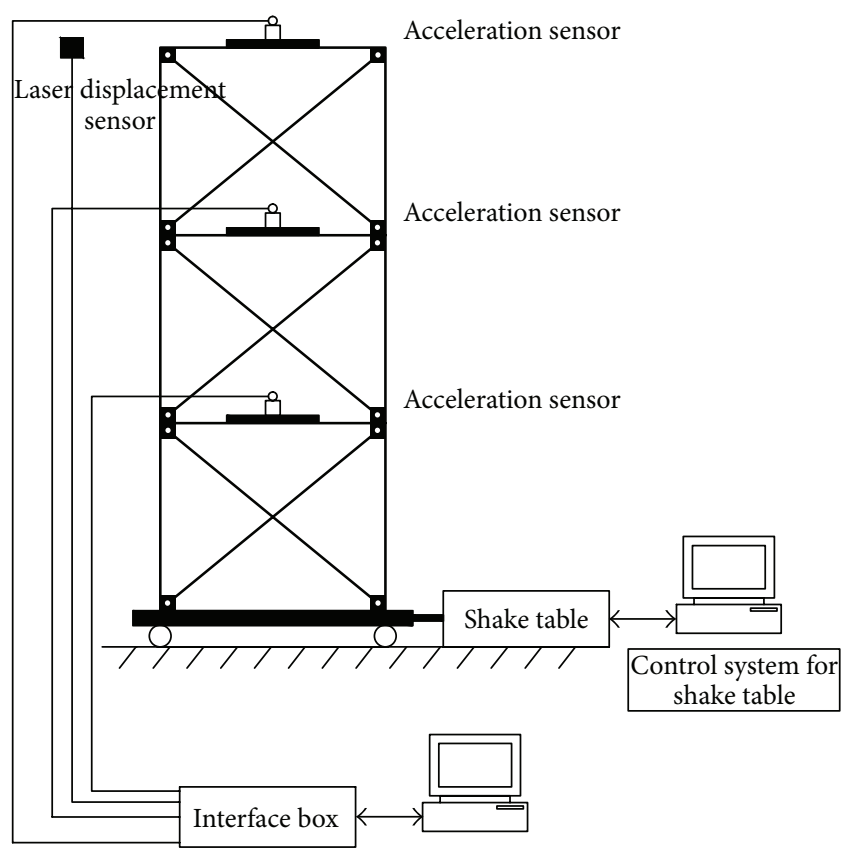

FIGURE 13: The schematic for experiment setup.

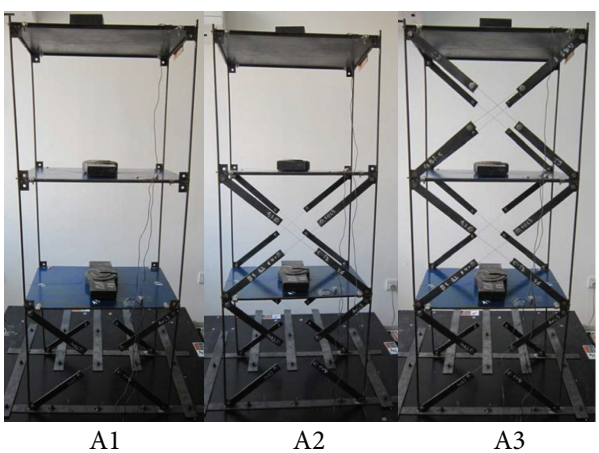

Figure 14: Photos for experiment schemes.

sine wave with a displacement amplitude of $3 \mathrm{~mm}$ and a frequency of $2 \mathrm{~Hz}$ for the steel frame structure under the different control schemes. Through the frequency spectrum analysis on the measured vibration data of the steel frame structure, the natural frequencies of the structure under different control schemes are obtained, as shown in Table 5.

Table 5 shows that the natural frequency of the frame structure installed SMA wire is improved compared with the frame structure without an SMA wire. 

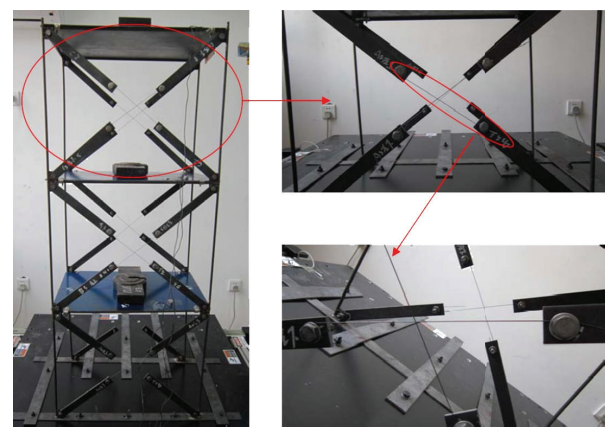

Figure 15: Photos for SMA dampers.

TABLE 5: Natural frequency and cycle of the structure under different control schemes.

\begin{tabular}{lcccc}
\hline Control scheme & A0 & A1 & A2 & A3 \\
\hline Natural frequency/Hz & 1.6964 & 2.2115 & 3.9380 & 6.0070 \\
Cycle/s & 0.5895 & 0.4522 & 0.2539 & 0.1665 \\
\hline
\end{tabular}

In order to better compare the maximum acceleration and displacement of the same story in the condition of the same seismic wave under the action of different control schemes, the passive control effect is defined by the following formula:

$$
\begin{array}{r}
J_{i, x}=\frac{\max \left\{\operatorname{abs}\left[x_{i, \text { unc. }}(t)\right]\right\}-\max \left\{\operatorname{abs}\left[x_{i, \text { cont. }}(t)\right]\right\}}{\max \left\{\operatorname{abs}\left[x_{i, \text { unc. }}(t)\right]\right\}} \\
\times 100 \%, \\
0 \leq i \leq 3 .
\end{array}
$$

In formula (11) $J_{i, x}$ is the control effect of the " $i$ " story peak response of the structure; $x_{i, \text { unc. }}$ and $x_{i, \text { cont. }}$ are the " $i$ " story peak displacement of the structure without control and structure with control, respectively. The speed and acceleration control effect can be derived in a similar way.

In structural vibration control, the acceleration of structure vibration should not be too large. The value of the acceleration can reflect both the value of the structural restoring force and the value of the structure stiffness.

The energy dissipation characteristics of the SMA wire can be further compared according to the comparative result of the acceleration of each story under different control schemes.

The comparison of the acceleration control effect for the steel frame structure under the Northridge wave action with the maximum acceleration of $0.20 \mathrm{~g}$ is shown in Figures 16 and 17. For the first floor, the maximum accelerations of schemes A0, A1, A2, and A3 are 2.96, 2.58, 2.40, and $2.08 \mathrm{~m} / \mathrm{s}^{2}$, respectively; For the second floor, the maximum accelerations of schemes A0, A1, A2, and A3 are 4.24, 3.57, 2.95 , and $2.57 \mathrm{~m} / \mathrm{s}^{2}$, respectively. For the third floor, the maximum accelerations of schemes A0, A1, A2, and A3 are $6.38,4.99,3.74$, and $3.24 \mathrm{~m} / \mathrm{s}^{2}$, respectively. At the top level, the maximum acceleration control effects are $21.79 \%$ for the control scheme A1, $41.38 \%$ for the control scheme A2, and $49.22 \%$ for the control scheme A3.

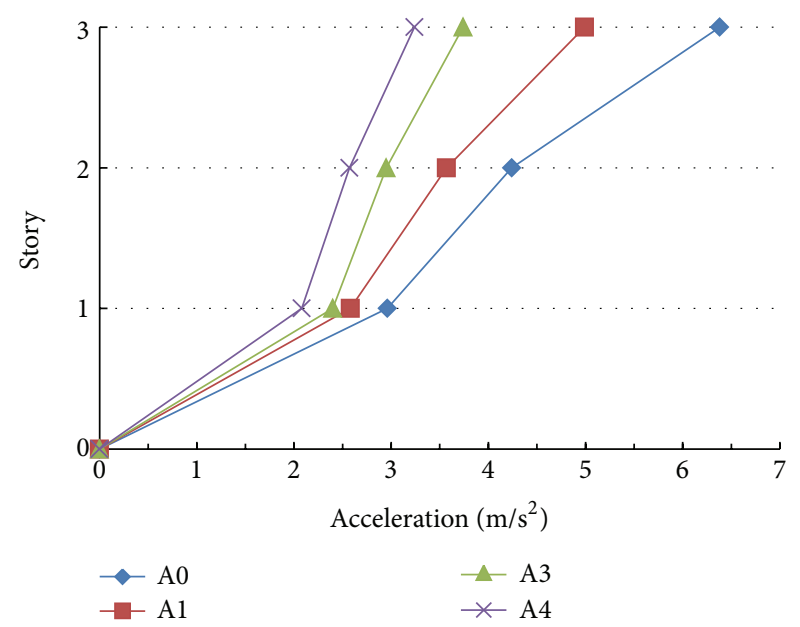

FIGURE 16: The peak acceleration for story under Northridge wave.

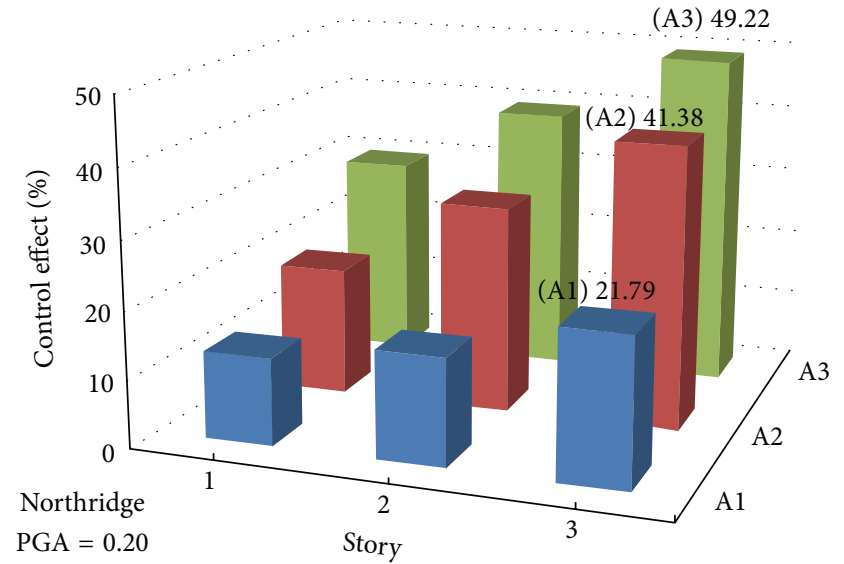

FIGURE 17: The peak acceleration control effect for story.

Three kinds of control schemes can effectively reduce the acceleration response of the structure. Among them, A2 and A3 reduce more significantly than A1. Comparing schemes $\mathrm{A} 2$ and $\mathrm{A} 3$, the control effect for the scheme A3 is 1.19 times $\mathrm{A} 2$, and the number of SMA wires for the scheme A3 is 1.5 times the scheme A2.

The comparison of the acceleration control effect for the steel frame structure under the El-Centro wave action with the maximum acceleration of $0.20 \mathrm{~g}$ is shown in Figures 18 and 19, respectively. For the first floor, the maximum accelerations of schemes A0, A1, A2, and A3 are 3.22, 2.19, 1.98, and $1.82 \mathrm{~m} / \mathrm{s}^{2}$, respectively. For the second floor, the maximum accelerations of schemes $\mathrm{A} 0, \mathrm{~A} 1, \mathrm{~A} 2$, and $\mathrm{A} 3$ are 3.99, 2.84, 2.49 , and $2.13 \mathrm{~m} / \mathrm{s}^{2}$, respectively. For the third floor, the maximum accelerations of schemes $\mathrm{A} 0, \mathrm{~A} 1, \mathrm{~A} 2$, and $\mathrm{A} 3$ are $4.31,3.35,2.86$, and $2.42 \mathrm{~m} / \mathrm{s}^{2}$, respectively. At the top level, the maximum acceleration control effects are $22.27 \%$ for the scheme A1, 33.64\% for the scheme A2, and $43.85 \%$ for the scheme A3.

Three kinds of control schemes can effectively reduce the acceleration response of the structure. Among them, A2 and A3 reduce with more significance. Comparing schemes A2 


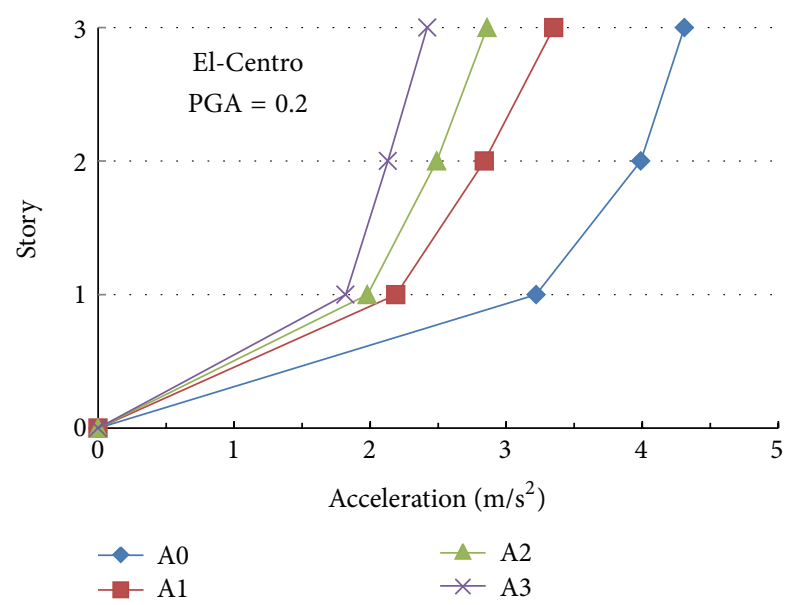

FIGURE 18: The story peak acceleration under El-Centro wave.

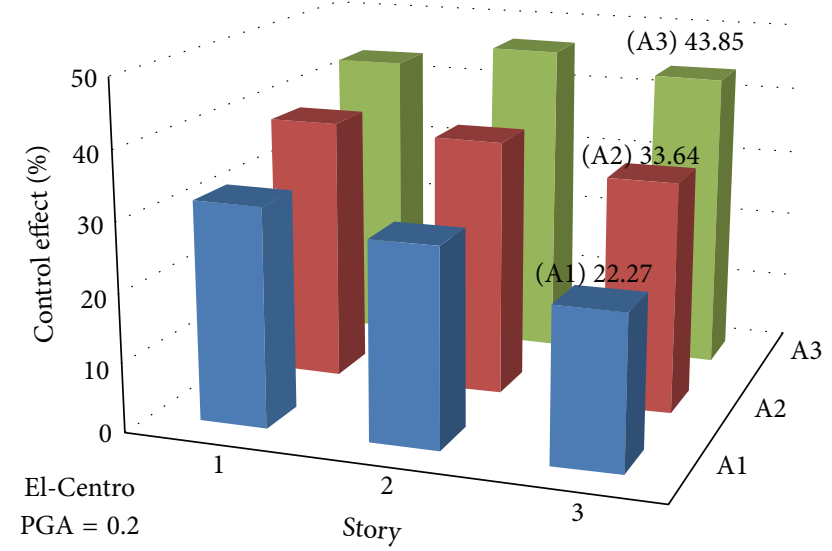

FIGURE 19: The story peak acceleration control effect.

and A3, the control effect with the scheme A3 is 1.3 times A2, and the number of SMA wire for the scheme A3 is 1.5 times scheme A2.

The comparison of the displacement control effect for the steel frame structure under the Northridge wave action with the maximum acceleration of $0.20 \mathrm{~g}$ is shown in Figure 20. For the first floor, the maximum displacement of schemes A0, A1, A2, and A3 are 1.0, 0.7, 0.5 and $0.25 \mathrm{~cm}$, respectively; For the second floor, the maximum displacements of schemes A0, $\mathrm{A} 1, \mathrm{~A} 2$, and $\mathrm{A} 3$ are $1.9,0.9,0.7$, and $0.5 \mathrm{~cm}$, respectively. For the third floor, the maximum displacements of schemes A0, A1, $\mathrm{A} 2$, and $\mathrm{A} 3$ are $2.7,1.2,1.0$, and $0.8 \mathrm{~cm}$, respectively.

The comparison of the displacement control effect for the steel frame structure under the El-Centro wave action with the maximum acceleration of $0.20 \mathrm{~g}$ is shown in Figure 21. For the first floor, the maximum displacements of schemes A0, $\mathrm{A} 1, \mathrm{~A} 2$, and $\mathrm{A} 3$ are $3.2,0.6,0.4$, and $0.25 \mathrm{~cm}$, respectively. For the second floor, the maximum displacements of schemes A0, $\mathrm{A} 1, \mathrm{~A} 2$, and $\mathrm{A} 3$ are $3.9,0.9,0.7$, and $0.55 \mathrm{~cm}$, respectively. For the third floor, the maximum displacements of schemes A0, $\mathrm{A} 1, \mathrm{~A} 2$, and $\mathrm{A} 3$ are $4.2,1.1,0.9$, and $0.7 \mathrm{~cm}$, respectively.

From the above results, the SMA wires installed in diagonals between the stories of the structure have good

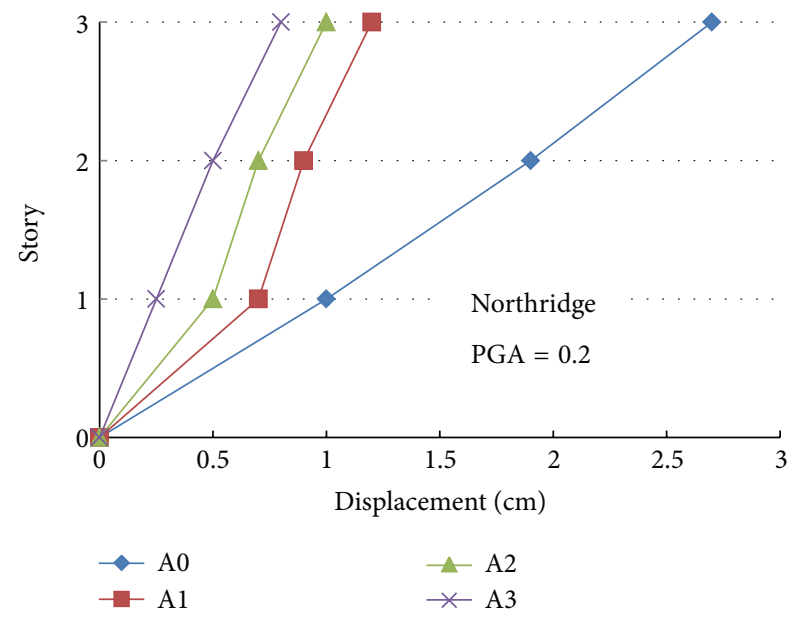

FIgURE 20: The story peak displacement under Northridge wave.

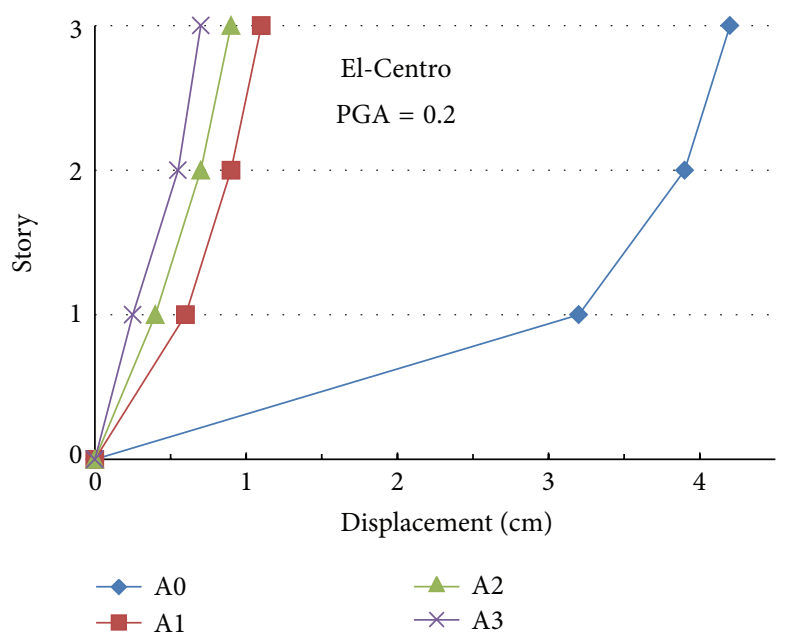

FIgURE 21: The story peak displacement under El-Centro wave.

effect on the control of acceleration and displacement, which can effectively reduce acceleration and displacement and play a good role in protecting the structure. However, from an economical view, the scheme A2 is more reasonable and effective. Therefore, the SMA wires do not need to be installed on each story.

\subsection{Comparison of Numerical Analysis and Experimental} Results. The comparison curve of the natural frequency can be seen in Figure 22. The natural frequency value of the numerical simulation model is slightly lower than that of the steel frame structure, which indicates that the numerical simulation and the test can both reflect the characteristics of the researched object. The natural frequency of the frame structure with SMA wires is improved compared with the frame structure without SMA wires, which shows that SMA wires can change the natural frequency of the frame structure, increasing the stiffness in the structure and the ability of seismic resistance. 


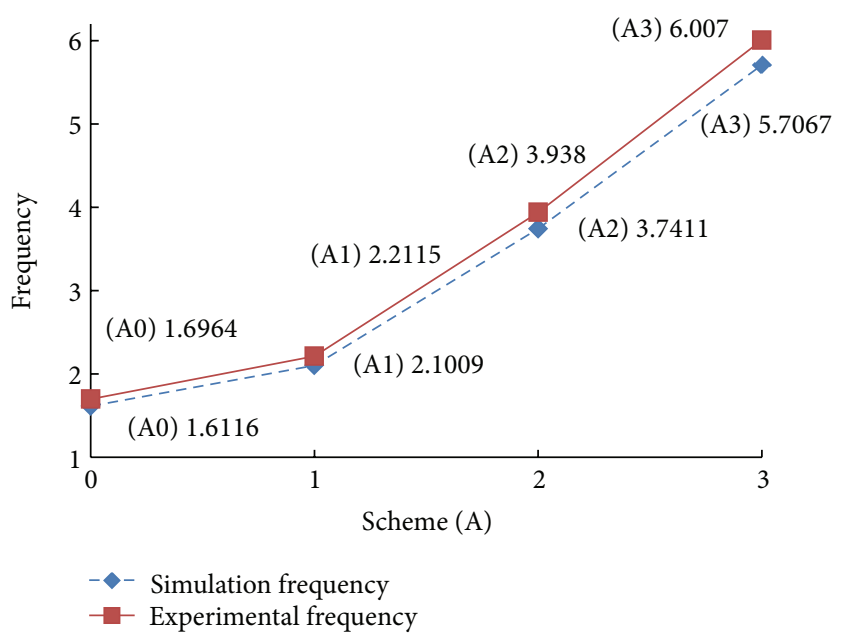

Figure 22: Frequency change for different schemes.

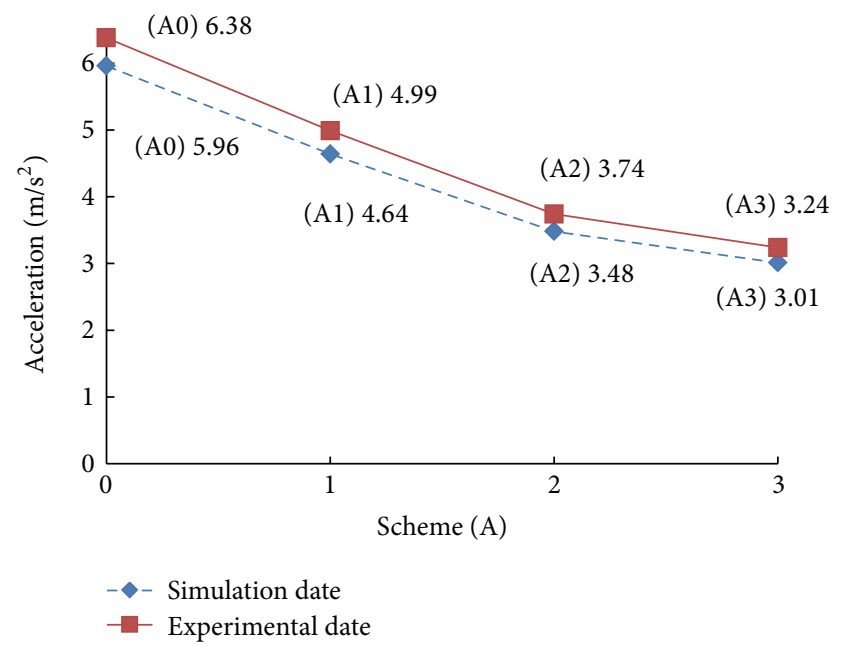

FIgURE 23: The top peak acceleration under Northridge wave.

Taking the data of the top floor as an example, the comparison of the acceleration and displacement of the numerical simulation and shaking table test under the action of the Northridge wave with the maximum acceleration of $0.20 \mathrm{~g}$ is shown in Figures 23 and 24. Under the same seismic action of different control schemes, the simulation data is relatively smaller than the test data which shows that the simulation and experimental data have certain differences. The acceleration and displacement are basically close to each other with a consistent trend. The SMA wires installed on diagonals between the stories of the structure have a very good effect on the control of acceleration and displacement of structure. All of the three kinds of control schemes can effectively reduce the acceleration and displacement of the stories of the structure and can provide good protection to the structure. However, from an economical view, the scheme A2 is more reasonable and effective. Therefore, installing SMA wires at each story is unnecessary.

Taking the data of the top floor as an example, under the action of another typical El-Centro wave, the comparison

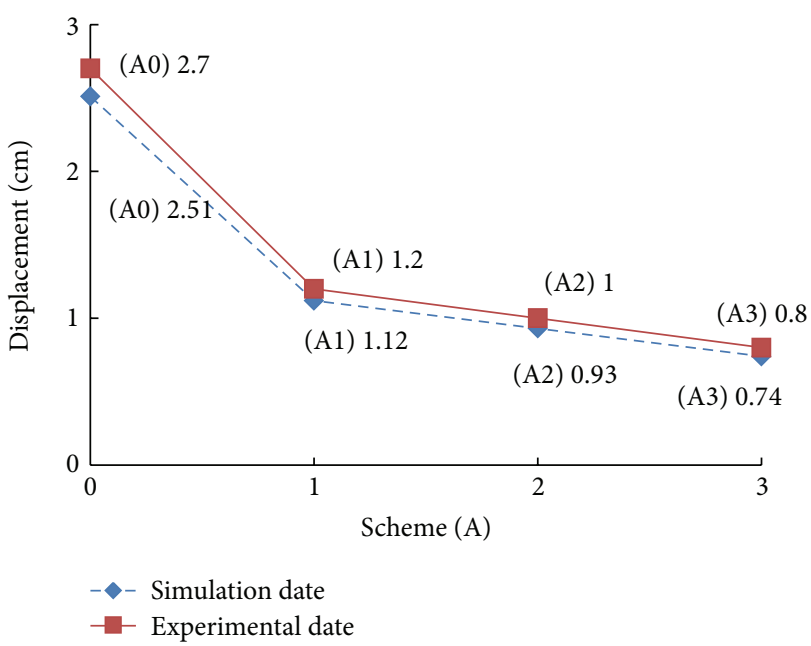

FIgURE 24: The top peak displacement under Northridge wave.

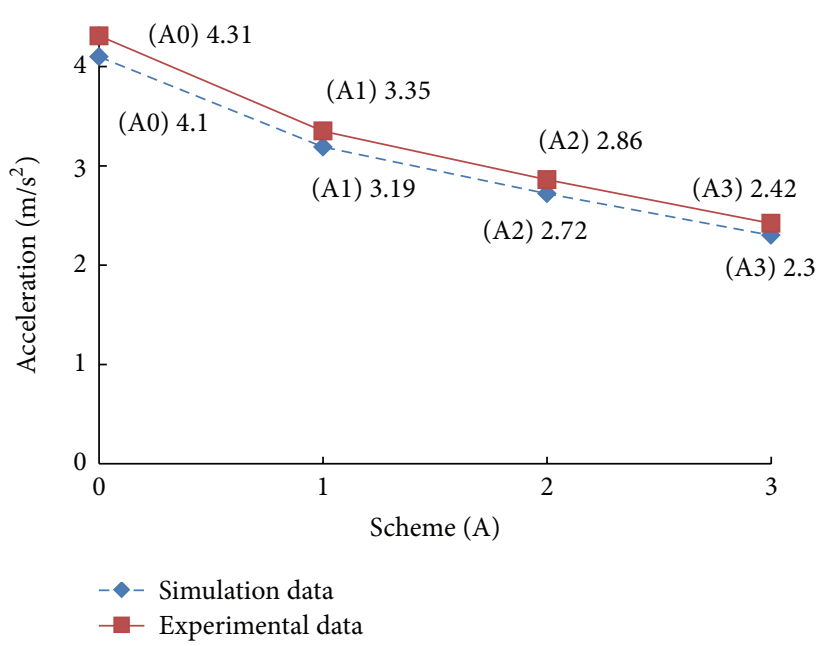

FIGURE 25: The top peak acceleration under El-Centro wave.

curves of simulation and experimental acceleration and displacement are shown in Figures 25 and 26, respectively. Through data analysis, the same conclusion under the action of the Northridge wave can be derived, which shows that, under the effect of different seismic waves, the different control schemes can effectively reduce the seismic response of the steel frame structure, but, from the perspective of effectiveness and economy, the scheme A2 is obviously more reasonable and effective.

\section{Conclusions}

(a) Based on the loading-unloading cycle test of the shape memory alloy wire, a stable and full stress-strain hysteresis curve can be derived, and the excellent performance of superelasticity of shape memory alloys can be experimentally validated. Therefore, in the practical engineering application of SMA wires for structural vibration control, certain cycles of training 


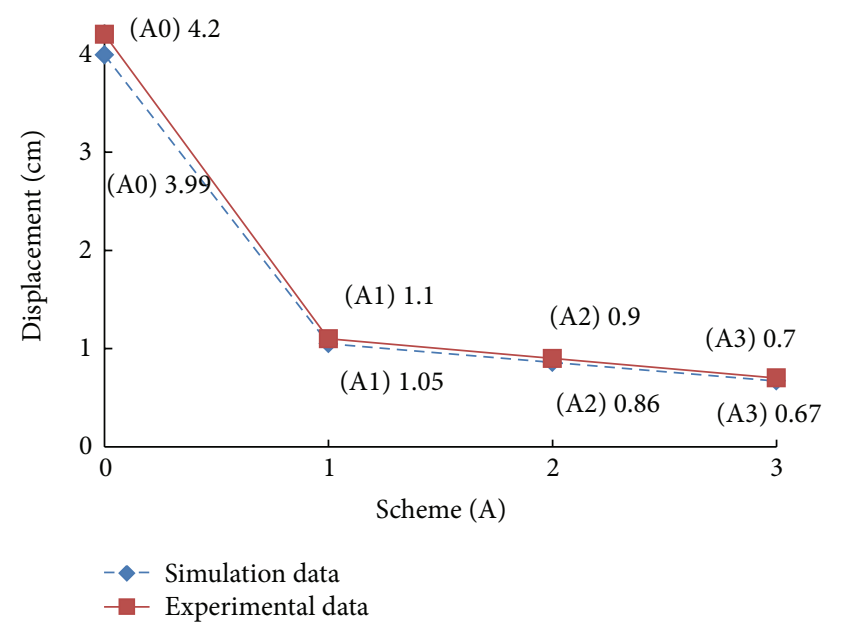

FIgURE 26: The top peak displacement under El-Centro wave.

should be carried out in advance in order to obtain the stable superelastic properties.

(b) For frame structures, the proposed design of the SMA superelasticity damper has the characteristics of convenient installation and the initial strain should be set as installing SMA dampers to make the SMA damper quickly enter into the work state in the earthquake, thus allowing maximally absorption and dissipation of seismic energy and achieving a better damping effect.

(c) Through shaking table test and numerical simulation of the three story steel frame structure with and without SMA dampers, it is validated that the SMA damper can change the natural frequency of the structure, improve the stiffness of structure, reduce acceleration, velocity, and displacement response of a steel frame structure in the process of an earthquake, and effectively improve the seismic capability of a structure.

(d) Under the action of two different seismic waves, three kinds of the developed control schemes can effectively reduce the seismic response of the structure, and the schemes $\mathrm{A} 2$ and $\mathrm{A} 3$ can reduce the value more significantly with better energy absorption. However, from the economic point of view, the scheme A2 is more reasonable and effective. Therefore, it is unnecessary to install an SMA damper on each story in practical engineering.

\section{Acknowledgments}

This work was financially supported in part by the National Natural Science Foundation of China (Grant no. 51278373 and Grant no. 51121005), the Natural Science Foundation of Liaoning Province (201202180), the Science Foundation of Liaoning Education Department (L2012214), and Key Laboratory Foundation of Liaoning Province (JG2009-18), as well as Liaoning Electric Power Survey \& Design Institute Foundation.

\section{References}

[1] Z. Fulin, Engineering Structure Vibration Control, The Earthquake Publishing House, Beijing, China, 1997.

[2] L.-F. Ni, A.-Q. Li, X.-B. Zuo, and Q.-F. Chen, "Experimental study of SMA superelastic damper for structural vibration control," Journal of Earthquake Engineering and Engineering Vibration, vol. 23, no. 5, pp. 205-208, 2003.

[3] H.-N. Li, H. Qian, G.-B. Song, and D.-W. Gao, "Type of shape memory alloy damper: design, experiment and numerical simulation," Journal of Vibration Engineering, vol. 21, no. 2, pp. 179-184, 2008.

[4] H. Li and C.-X. Mao, "Experimental investigation of earthquake response reduction of buildings with added two types of SMA passive energy dissipation devices," Journal of Earthquake Engineering and Engineering Vibration, vol. 23, no. 1, pp. 133-139, 2003.

[5] C. Mao, H. Li, and J. Ou, "Experimental and analytical investigations of shape memory alloy as passive energy dissipation device for seismic response reduction of building," Journal of Building Structures, vol. 26, no. 3, pp. 38-44, 2005.

[6] Y. Han, A. Li, and P. Lin, "Experimental study of frame structure vibration control by using shape memory alloy damper," Journal of Southeast University, vol. 30, no. 4, pp. 16-20, 2000.

[7] S.-D. Xue, L. Wang, and P. Zhuang, "Design and performance study of a SMA incorporated friction damper," World Information on Earthquake Engineering, vol. 22, no. 2, pp. 1-6, 2006.

[8] S. Yan, Q. Wang, and W. Wang, "Design and experimental investigation on a new type of SMA-fluid viscous damper," in Proceedings of the 12th ASCE Aerospace Division International Conference on Earth and Space, pp. 3198-3206, Honolulu, Hawaii, USA, March 2010.

[9] K. Tanaka, “Thermomechanical sketch of shape memory effect: one-dimensional tensile behavior," Res Mechanica, vol. 18, no. 3, pp. 251-263, 1986.

[10] C. Liang and C. A. Roger, "One-dimensional thermomechanical constitutive relations of shape memory materials," Journal of Mechanics and Physics of Solids, vol. 41, no. 3, pp. 541-571, 1993.

[11] L. C. Brinson and M. S. Huang, "Simplifications and comparisons of shape memory alloy constitutive models," Journal of Intelligent Material Systems and Structures, vol. 7, no. 1, pp. 108114, 1996.

[12] S. Wang, S. Su, and Y. Shen, "Seismic response analysis for passive structural control with shape memory alloy tendons," China Civil Engineering Journal, vol. 2, no. 1, pp. 56-62, 2000.

[13] R. W. Clough and J. Penzien, Dynamics of Structures, Berkeley: Computers \& Structures Inc., 3rd edition, 2003. 


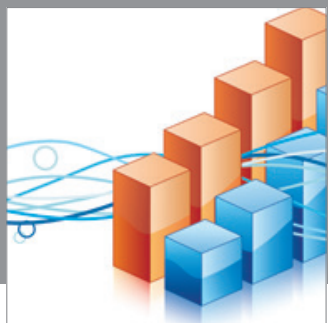

Advances in

Operations Research

mansans

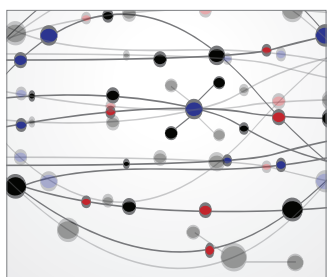

The Scientific World Journal
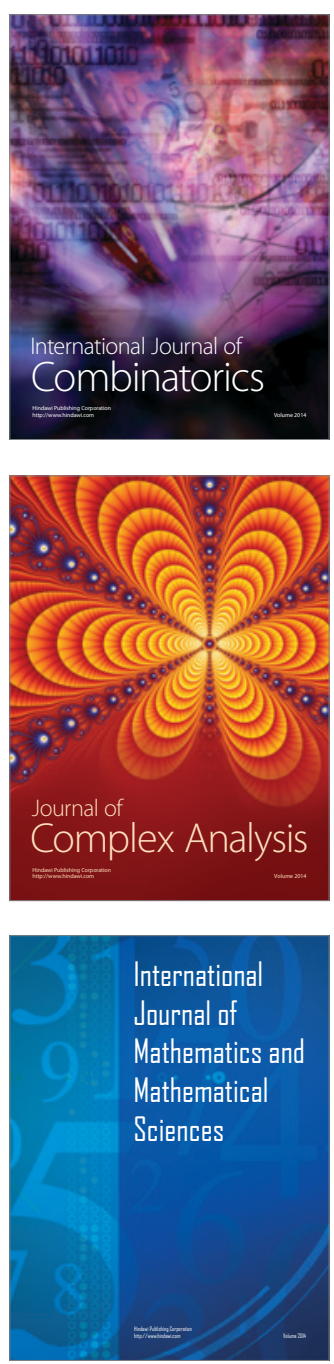
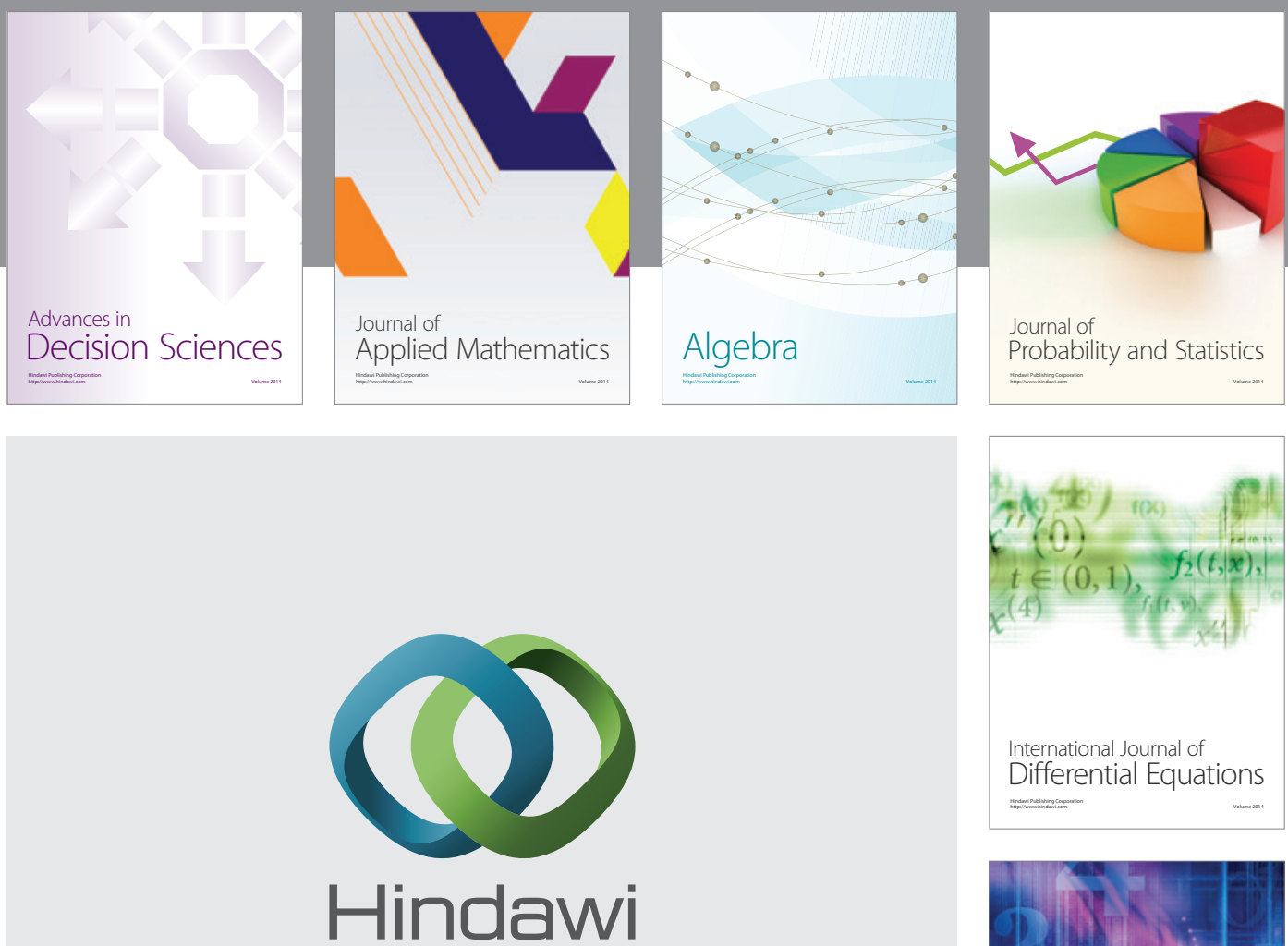

Submit your manuscripts at http://www.hindawi.com
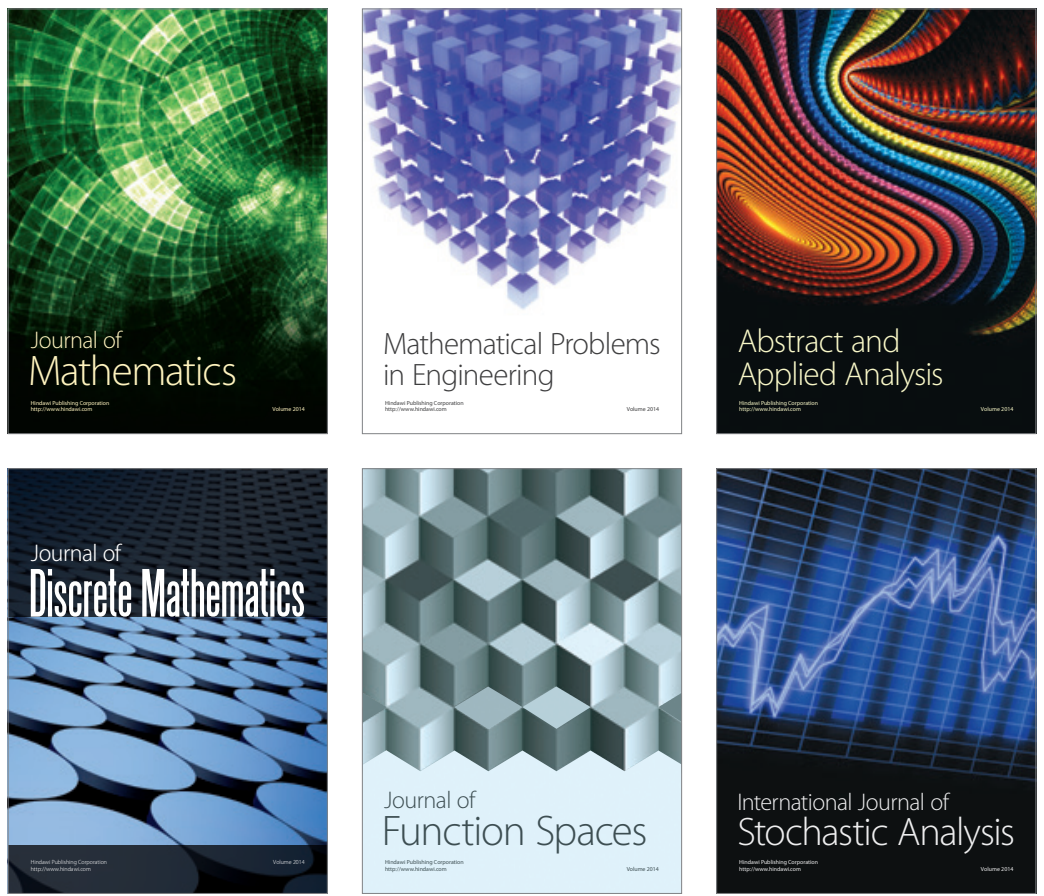

Journal of

Function Spaces

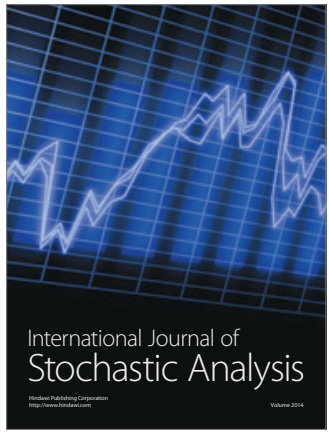

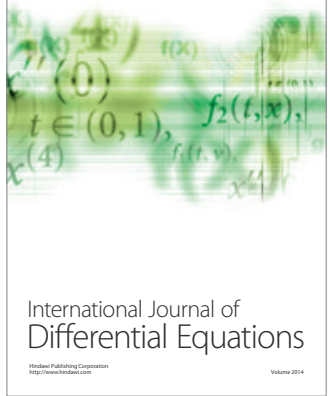
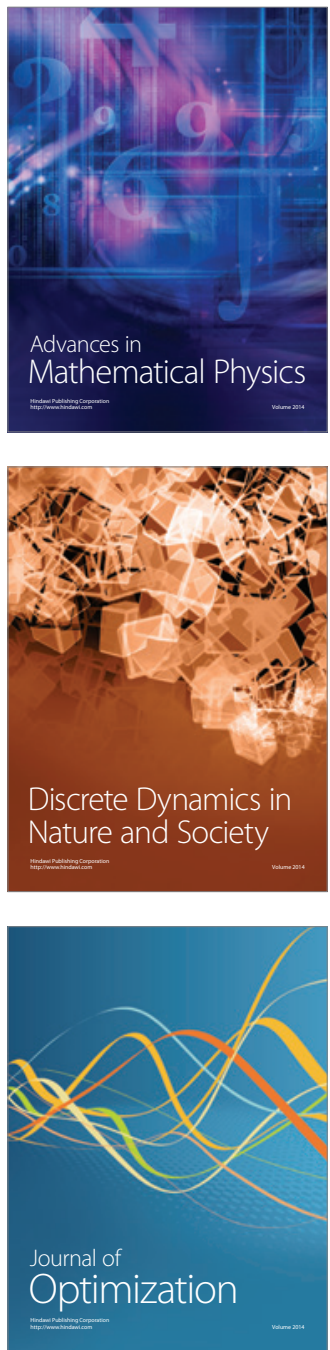